\title{
Efficacy of sacubitril/valsartan versus olmesartan in Japanese patients with essential hypertension: a randomized, double-blind, multicenter study
}

\author{
Hiromi Rakugi ${ }^{1} \cdot$ Kazuomi Kario $^{2} \cdot$ Masako Yamaguchi $^{3} \cdot$ Takayoshi Sasajima $^{3} \cdot$ Hiromi Gotou $^{3} \cdot$ Jack Zhang $^{4}$
}

Received: 5 July 2021 / Revised: 20 October 2021 / Accepted: 9 November 2021 / Published online: 21 January 2022

(c) The Author(s) 2022. This article is published with open access

\begin{abstract}
This phase III study assessed the efficacy and safety of sacubitril/valsartan compared with those of olmesartan in Japanese patients with essential hypertension. Patients $(n=1161$, aged $\geq 20$ years) with mild to moderate hypertension (mean sitting systolic blood pressure [msSBP] $\geq 150$ to $<180 \mathrm{mmHg}$ ) were randomized to receive sacubitril/valsartan $200 \mathrm{mg}(n=387)$, sacubitril/valsartan $400 \mathrm{mg}(n=385)$, or olmesartan $20 \mathrm{mg}(n=389)$ once daily for 8 weeks. The primary assessment was a reduction in msSBP from baseline with sacubitril/valsartan $200 \mathrm{mg}$ vs. olmesartan $20 \mathrm{mg}$ at Week 8 . Secondary assessments included msSBP reduction with sacubitril/valsartan $400 \mathrm{mg}$ vs. olmesartan at Week 8 and reductions in mean sitting diastolic blood pressure (msDBP), mean sitting pulse pressure (msPP), and overall blood pressure (BP) control rate for all treatment groups at Week 8 . Sacubitril/valsartan $200 \mathrm{mg}$ provided a significantly greater reduction in msSBP from baseline than olmesartan at Week 8 (between-treatment difference: $-5.01 \mathrm{mmHg}$ [95\% confidence interval: -6.95 to $-3.06 \mathrm{mmHg}, P<$ 0.001 for noninferiority and superiority]). Greater reductions in msSBP with sacubitril/valsartan $400 \mathrm{mg}$ vs. olmesartan, as well as in msDBP and msPP with both doses of sacubitril/valsartan vs. olmesartan $(P<0.05$ for all $)$, were also observed. Patients treated with sacubitril/valsartan achieved an overall higher BP control rate. The safety and tolerability profiles of sacubitril/valsartan were generally comparable to those of olmesartan. The adverse event rate with sacubitril/valsartan was not dose-dependent. Treatment with sacubitril/valsartan was effective and provided superior BP reduction, with a higher proportion of patients achieving target BP goals than treatment with olmesartan in Japanese patients with mild to moderate essential hypertension.
\end{abstract}

Keywords Angiotensin receptor neprilysin inhibitor $\cdot$ Japanese $\cdot$ Olmesartan $\cdot$ Sacubitril/valsartan $\cdot$ Systolic hypertension

This study was presented at the AHA 2013 and AHA 2014 and at HBPR 2013 and HBPR 2014.

Supplementary information The online version contains supplementary material available at https://doi.org/10.1038/s41440021-00819-7.

Hiromi Rakugi

rakugi@geriat.med.osaka-u-ac.jp

1 Department of Geriatric and General Medicine, Osaka University Graduate School of Medicine, Osaka, Japan

2 Division of Cardiovascular Medicine, Department of Medicine, Jichi Medical University School of Medicine, Tochigi, Japan

3 Novartis Pharma K. K, Tokyo, Japan

4 Novartis Pharmaceuticals Corporation, East Hanover, NJ, USA

\section{Introduction}

Hypertension is a major risk factor for cardiovascular (CV) diseases, and its prevalence is rapidly increasing in Asia, including Japan [1, 2]. An estimated 43 million individuals in Japan are affected by hypertension, and the incidence of hypertension is expected to increase in view of the growing elderly population [3, 4]. Despite the availability of a large number of recommended treatment options, blood pressure (BP) control remains inadequate in the majority of Japanese patients [3,5], especially in elderly patients, generally because of a lack of systolic blood pressure (SBP) control. New therapeutic options that target the underlying pathophysiology of systolic hypertension would therefore be beneficial in reducing the burden of this condition.

Sacubitril valsartan sodium hydrate (LCZ696, sacubitril/ valsartan), a first-in-class angiotensin receptor neprilysin 


\section{Graphical Abstract}

Treatment with sacubitril/valsartan is effective and provided superior blood pressure (BP) reductions with a higher proportion of patients achieving target BP goals versus olmesartan in Japanese patients with mild-to-moderate essential hypertension.

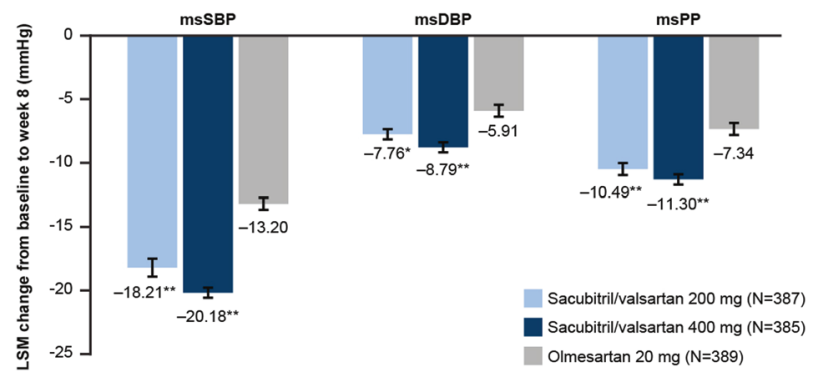

inhibitor (ARNI) that provides simultaneous neprilysin inhibition and angiotensin II receptor-1 blockade, has been approved for the treatment of heart failure with reduced ejection fraction (HFrEF) in several countries worldwide in view of its superior benefits over enalapril demonstrated in the PARADIGM-HF trial. Sacubitril/valsartan has been recently approved in Japan for the treatment of chronic heart failure [6-12]. The recent expansion of the indication for sacubitril/valsartan in the United States also allows the treatment of adults with a left ventricular ejection fraction below normal [13].

Neprilysin inhibition increases circulating levels of natriuretic peptides (NPs), which promote natriuresis, diuresis, vasodilation, and endothelial permeability and inhibit the reninangiotensin-aldosterone system (RAAS), the sympathetic nervous system (SNS), aldosterone secretion, and fibrosis; these actions confer cardiac, vascular, and renal protection [14-16]. Sacubitril/valsartan has demonstrated superior reductions in systolic and pulse pressures in previous studies in both Western and Asian patients with mild to moderate hypertension [7, 17] compared with valsartan [7] and placebo [17], respectively. Long-term use of sacubitril/valsartan provided significant BP reductions from baseline in Asian patients with mild to moderate hypertension [18]. The efficacy and safety of sacubitril/ valsartan has previously been demonstrated in Japanese patients with severe hypertension [19] and in patients with hypertension and renal impairment without a decline in renal function [20].

Olmesartan is a commonly prescribed angiotensin receptor blocker (ARB) for the management of systolic hypertension among Asians. Moreover, olmesartan was considered the most potent ARB when the current study was designed [21, 22], while more recent evidence suggests that olmesartan has safety and efficacy profiles that are similar to those of other ARBs [23-25].

Sacubitril/valsartan possesses activities of both angiotensin receptor blocking and neprilysin inhibition [26]; it is expected to demonstrate enhanced antihypertensive effects compared to an ARB. Previous studies have also demonstrated superior benefits of sacubitril/valsartan over olmesartan in reducing BP in patients with mild to moderate hypertension [27, 28]. However, the efficacy and safety of sacubitril/valsartan compared with those of olmesartan are not well established in Japanese patients with hypertension. Therefore, in the present phase III study, we assessed the BP-lowering efficacy and safety of sacubitril/valsartan in Japanese patients with mild to moderate essential hypertension and compared them with those of olmesartan.

\section{Methods}

\section{Study design and patients}

This was a multicenter, randomized, double-blind, parallelgroup, and active-controlled study (Supplementary Fig. S1) conducted between June 2012 and April 2013 in Japan. This study is registered with ClinicalTrials.gov (identifier: NCT01599104).

Male or female Japanese patients aged $\geq 20$ years with either treated or untreated mild to moderate systolic hypertension were eligible for this study. Elderly patients $(\geq$ 65 years) were recruited to make up $\sim 30 \%$ of the study population. Treated patients, defined as patients having a history of hypertension receiving antihypertensive medications within 4 weeks prior to screening, with mean sitting systolic blood pressure (msSBP) ranging from $\geq 150$ to $<180 \mathrm{mmHg}$ at randomization and $\geq 140$ to $<180 \mathrm{mmHg}$ at the visit immediately before randomization, were included. Untreated patients, defined as either (1) newly diagnosed hypertensive patients who had never taken any antihypertensive medications or (2) patients having a history of hypertension who had not been taking any antihypertensive medications for at least 4 weeks prior to screening and had msSBP ranging from $\geq 150$ to $<180 \mathrm{mmHg}$ at both screening and randomization, were included. 
Patients with severe hypertension (mean sitting diastolic blood pressure $[\mathrm{msDBP}] \geq 110 \mathrm{mmHg}$ or $\mathrm{msSBP} \geq 180$ $\mathrm{mmHg}$ ) or secondary forms of hypertension were excluded from the study. For patient safety, the study also excluded patients with a history of angioedema, stroke or transient ischemic cerebral attack, myocardial infarction, coronary bypass surgery, or any percutaneous coronary intervention during the 12 months prior to screening. Pregnant or nursing mothers and women of childbearing potential were also excluded.

Following screening, prior antihypertensive medication was stopped, or the dose was tapered, and all eligible patients entered a single-blind, placebo run-in period of 2-4 weeks. Patients who successfully completed the run-in and met entry criteria were randomized in a 1:1:1 ratio to double-blind treatment with sacubitril/valsartan $200 \mathrm{mg}$, sacubitril/valsartan $400 \mathrm{mg}$ (uptitrated following 1 week of $200 \mathrm{mg}$ ), or olmesartan $20 \mathrm{mg}$ once daily for 8 weeks. The dose of the active comparator, olmesartan $20 \mathrm{mg}$, is the commonly prescribed daily dose in Japan. All eligible patients were randomized using an Interactive Web Response System (IWRS). The identity of the treatments was concealed by using study drugs that were identical in packaging, labeling, administration schedule, and appearance. During the treatment period, trial participants were instructed to take two tablets and one capsule (the study drugs or matching placebo), with or without food, in the morning and at approximately the same time each day during the course of the study.

The study protocol was reviewed and approved by the institutional review board or independent ethics committee of each participating center. The study was conducted in accordance with the ICH Harmonized Tripartite Guidelines for Good Clinical Practice (with applicable local regulations) and the ethical principles in the Declaration of Helsinki. All patients provided written informed consent before the initiation of any study procedure.

\section{Efficacy assessments}

The primary assessment was testing the hypotheses of the noninferiority and superiority of sacubitril/valsartan $200 \mathrm{mg}$ compared with olmesartan $20 \mathrm{mg}$ in msSBP reductions from baseline at Week 8. Secondary assessments included reductions in msSBP from baseline with sacubitril/valsartan $400 \mathrm{mg}$ compared with olmesartan at Week 8; msDBP and mean sitting pulse pressure (msPP) from baseline at Week 8 ; the proportion of patients achieving successful BP control $(\mathrm{msSBP}<140 \mathrm{mmHg}$ and $\mathrm{msDBP}<90 \mathrm{mmHg}$ ), SBP control ( $\mathrm{msSBP}<140 \mathrm{mmHg}$ ), and DBP control (msDBP $<$ $90 \mathrm{mmHg}$ ); and the safety and tolerability of sacubitril/ valsartan $(200 \mathrm{mg}$ and $400 \mathrm{mg}$ ) compared with those of olmesartan. A subgroup analysis of the primary and secondary efficacy assessments (including msDBP, msPP, and overall BP control rate) by age group ( $<65$ years and $\geq 65$ years) was conducted. As a post hoc analysis, we assessed BP control rates according to the current Japanese Society of Hypertension (JSH) 2019 guideline (msSBP/ $\mathrm{msDBP}<130 / 80 \mathrm{mmHg}$ for $<75$ years old and $<140 / 90$ $\mathrm{mmHg}$ for $\geq 75$ years old). [4]

Clinical BP was measured at the trough using a validated automatic BP device (Omron HEM 7080IC). Blood pressure measurements were performed at screening through the end of the study at every visit. At each study visit, after the patient had been sitting for five minutes with their back supported and both feet placed on the floor, SBP and DBP were measured four times using the automatic BP monitor and an appropriate size cuff. Regular monitoring of clinical laboratory parameters was performed at a central laboratory, and regular assessments of vital signs and physical condition were conducted.

\section{Safety assessments}

Safety assessments included the monitoring of all adverse events (AEs) and serious AEs (SAEs) during the conduct of this study (from screening to Week 8 visit), as well as the regular monitoring of vital signs (from screening to Week 8 visit) and full clinical laboratory tests (at screening, randomization, the Week 4 visit, and the Week 8 visit).

\section{Statistical analysis}

The primary objective of this study was to compare the efficacy of sacubitril/valsartan $200 \mathrm{mg}$ with that of olmesartan $20 \mathrm{mg}$ by evaluating (i) the hypothesis of the noninferiority of sacubitril/valsartan $200 \mathrm{mg}$ vs. olmesartan 20 $\mathrm{mg}$ for a decrease in msSBP from baseline and (ii) if the hypothesis of noninferiority was met, the hypothesis of the superiority of sacubitril/valsartan $200 \mathrm{mg}$ over olmesartan $20 \mathrm{mg}$ for a decrease in msSBP from baseline was tested.

The primary analysis of the change in msSBP from baseline was conducted using a one-way analysis of covariance (ANCOVA) model with treatment as a factor and baseline msSBP as a covariate.

Sacubitril/valsartan $200 \mathrm{mg}$ was considered noninferior to olmesartan $20 \mathrm{mg}$ if the result of the noninferiority test was statistically significant. The statistical test was made at a one-sided significance level of 0.025 .

If the result of the noninferiority test was statistically significant, a superiority test was performed at a two-sided significance level of 0.05 , where superiority for sacubitril/ valsartan $200 \mathrm{mg}$ vs. olmesartan $20 \mathrm{mg}$ was considered to be achieved if the test was statistically significant in favor of sacubitril/valsartan. The continuous secondary endpoints were analyzed using a one-way ANCOVA model with the 
corresponding baseline value as a covariate. The BP control rates were analyzed using a logistic regression model with treatment as a factor and baseline value as a covariate. Summary statistics are presented for the age subgroup (aged $>65$ years) for the primary and secondary variables. For both primary and secondary endpoints, missing values at Week 8 were imputed with the last postbaseline measurement as the last observation carried forward (LOCF), and analysis was performed for the full analysis set (FAS). For secondary endpoints, no multiplicity adjustment was made; therefore, statistical interpretations should be made with caution.

The frequencies of AEs, SAEs, and notable laboratory abnormalities were measured using the safety set (SAF) of all patients who received at least one dose of double-blind study medication.

\section{Sample size calculation}

A sample size of 342 patients completing the study per group was targeted based on the primary efficacy variable and an SD of $14 \mathrm{mmHg}$ to attain $90 \%$ power to detect a change of $3.5 \mathrm{mmHg}$ at a two-sided significance level of 0.05 to test the hypothesis that sacubitril/valsartan $200 \mathrm{mg}$ is superior to olmesartan $20 \mathrm{mg}$. Assuming a 10\% drop-out rate, the total targeted sample size planned for randomization was 1140 patients. The sample size had $\geq 90 \%$ power for the noninferiority test, with a prespecified noninferiority margin of $2 \mathrm{mmHg}$, at a one-sided significance of 0.025 under the alternative hypothesis that sacubitril/valsartan $200 \mathrm{mg}$ has a greater msSBP reduction of $\geq 1.5 \mathrm{mmHg}$ than the olmesartan 20-mg treatment group.

\section{Results}

\section{Patients}

Of the 1161 randomized patients, 1105 (95.2\%) completed the study (Fig. 1). Common reasons for discontinuation were AEs (2.2\%) and a lack of efficacy (1.6\%). Total discontinuation and discontinuation due to AEs or a lack of efficacy were more frequent in the olmesartan group than in the sacubitril/valsartan group. The majority of patients were male $(70.5 \%)$, the mean age was 58.7 years, and approximately $32.9 \%$ of patients were elderly patients (aged $\geq 65$ years). The mean duration of hypertension was 8.5 years, and $74.8 \%$ of the patients were treated with antihypertensive medications (Table 1).

\section{Efficacy}

\section{Clinic blood pressure}

Sacubitril/valsartan $200 \mathrm{mg}$ provided superior msSBP reduction from baseline over olmesartan at 8 weeks, with a between-treatment difference $(95 \%$ confidence interval [CI]) of $-5.01 \mathrm{mmHg}(-6.95,-3.06 ; P<0.001$ for noninferiority and superiority) (Fig. 2). Similarly, sacubitril/ valsartan $400 \mathrm{mg}$ also provided greater msSBP reductions from baseline than olmesartan at Week 8, with a betweentreatment difference $(95 \% \mathrm{CI})$ of $-6.97(-8.92,-5.03 ; P<$ $0.001) \mathrm{mmHg}$. Similar results were observed for msDBP and msPP, with both doses of sacubitril/valsartan providing greater reductions from baseline to Week 8 than olmesartan ( $P \leq 0.001$ for all) (Fig. 2). Sacubitril/valsartan $400 \mathrm{mg}$ provided numerically greater msSBP, msDBP, and $\mathrm{msPP}$ reductions than sacubitril/valsartan $200 \mathrm{mg}$.

In the subgroup analysis by age group, sacubitril/valsartan $200 \mathrm{mg}$ and $400 \mathrm{mg}$ showed numerically greater msSBP reductions from baseline to Week 8 than olmesartan in both elderly (aged $\geq 65$ years) $(-18.78,-19.52$, and $-11.51 \mathrm{mmHg}$, respectively), and nonelderly patients (aged $<65$ years) $(-17.94,-20.53$, and $-14.10 \mathrm{mmHg}$, respectively) (Table 2). The magnitude of the difference between the sacubitril/valsartan groups and the olmesartan group appeared to be greater in elderly patients. Similar results were observed for msDBP and msPP, with both doses of sacubitril/valsartan resulting in numerically greater reductions from baseline to Week 8 than olmesartan
Fig. 1 Patient disposition. Data are presented as $\mathrm{n}(\%)$.

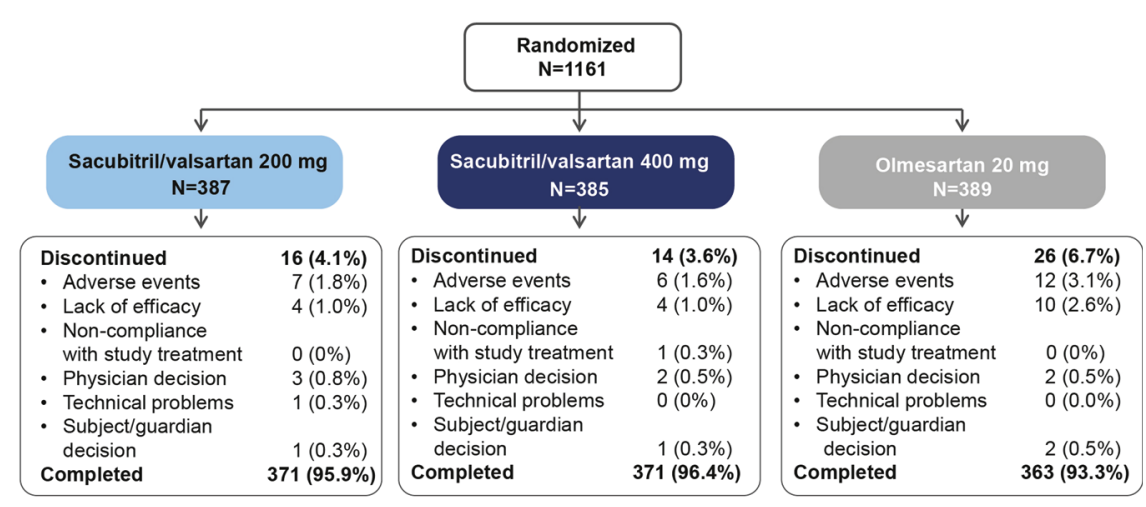


Table 1 Patient demographics and baseline characteristics

\begin{tabular}{|c|c|c|c|c|}
\hline $\begin{array}{l}\text { Demographic/baseline } \\
\text { variable }\end{array}$ & $\begin{array}{l}\text { Sacubitril/ } \\
\text { valsartan } 200 \mathrm{mg} \\
N=387\end{array}$ & $\begin{array}{l}\text { Sacubitril/ } \\
\text { valsartan } 400 \mathrm{mg} \\
N=385\end{array}$ & $\begin{array}{l}\text { Olmesartan } 20 \mathrm{mg} \\
N=389\end{array}$ & $\begin{array}{l}\text { Total } \\
N=1161\end{array}$ \\
\hline Age (years) & $57.9 \pm 10.9$ & $58.7 \pm 10.5$ & $59.6 \pm 10.5$ & $58.7 \pm 10.6$ \\
\hline$\geq 65$ years, $n(\%)$ & $119(30.7)$ & $127(33.0)$ & $136(35.0)$ & $382(32.9)$ \\
\hline Male, $n(\%)$ & $264(68.2)$ & $268(69.6)$ & $286(73.5)$ & $818(70.5)$ \\
\hline \multicolumn{5}{|l|}{ Ethnicity, $n(\%)$} \\
\hline Japanese & $387(100.0)$ & $385(100.0)$ & $389(100.0)$ & $1161(100.0)$ \\
\hline BMI $\left(\mathrm{kg} / \mathrm{m}^{2}\right)$ & $25.4 \pm 3.7$ & $25.3 \pm 3.9$ & $25.6 \pm 3.8$ & $25.4 \pm 3.8$ \\
\hline $\begin{array}{l}\text { Duration of hypertension } \\
\text { history (years) }\end{array}$ & $8.4 \pm 6.8$ & $8.3 \pm 6.7$ & $8.9 \pm 7.2$ & $8.5 \pm 6.9$ \\
\hline \multicolumn{5}{|c|}{ Antihypertensive medications, $n(\%)$} \\
\hline Treated*, $n(\%)$ & $281(72.6)$ & $283(73.5)$ & $304(78.1)$ & $868(74.8)$ \\
\hline Untreated, $n(\%)$ & $106(27.4)$ & $102(26.5)$ & $85(21.9)$ & $293(25.2)$ \\
\hline $\begin{array}{l}\text { Having a history of } \\
\text { hypertension**, } n(\%)\end{array}$ & $105(27.1)$ & $101(26.2)$ & $84(21.6)$ & $290(25.0)$ \\
\hline $\begin{array}{l}\text { Newly diagnosed with } \\
\text { hypertension }^{\#}, n(\%)\end{array}$ & $1(0.3)$ & $1(0.3)$ & $1(0.3)$ & $3(0.3)$ \\
\hline Diabetes, $n(\%)$ & $29(7.5)$ & $35(9.1)$ & $43(11.1)$ & $107(9.2)$ \\
\hline \multicolumn{5}{|c|}{ eGFR group $\left(\mathrm{mL} / \mathrm{min} / 1.73 \mathrm{~m}^{2}\right)$} \\
\hline $30 \leq \mathrm{eGFR}<60, n(\%)$ & $90(23.3)$ & $113(29.4)$ & $131(33.7)$ & $334(28.8)$ \\
\hline $60 \leq \mathrm{eGFR}<90, n(\%)$ & $275(71.1)$ & $250(64.9)$ & $242(62.2)$ & $767(66.1)$ \\
\hline $\mathrm{eGFR} \geq 90, n(\%)$ & $22(5.7)$ & $22(5.7)$ & $16(4.1)$ & $60(5.2)$ \\
\hline $\mathrm{msSBP}, \mathrm{mmHg}$ & $157.7 \pm 6.9$ & $158.4 \pm 7.3$ & $157.6 \pm 6.8$ & $157.9 \pm 7.0$ \\
\hline$<65$ years & $157.56 \pm 7.0$ & $157.53 \pm 6.7$ & $157.03 \pm 6.3$ & NA \\
\hline$\geq 65$ years & $158.01 \pm 6.8$ & $160.22 \pm 8.2$ & $158.78 \pm 7.4$ & NA \\
\hline msDBP, $\mathrm{mmHg}$ & $94.3 \pm 9.4$ & $94.8 \pm 9.8$ & $93.8 \pm 9.7$ & $94.3 \pm 9.6$ \\
\hline$<65$ years & $97.45 \pm 7.9$ & $97.94 \pm 8.2$ & $97.76 \pm 7.2$ & NA \\
\hline$\geq 65$ years & $87.08 \pm 8.6$ & $88.35 \pm 9.6$ & $86.48 \pm 9.3$ & NA \\
\hline $\mathrm{msPP}, \mathrm{mmHg}$ & $63.4 \pm 10.3$ & $63.6 \pm 11.3$ & $63.8 \pm 11.1$ & $63.6 \pm 10.9$ \\
\hline$<65$ years & $60.11 \pm 8.8$ & $59.59 \pm 9.5$ & $59.27 \pm 8.5$ & NA \\
\hline$\geq 65$ years & $70.94 \pm 9.3$ & $71.87 \pm 10.2$ & $72.31 \pm 10.5$ & NA \\
\hline
\end{tabular}

Data are presented as mean \pm standard deviation unless specified

$B M I$ body mass index, $D B P$ diastolic blood pressure, $e G F R$ estimated glomerular filtration rate, $m s$ mean sitting, $N A$ not available, $P P$ pulse pressure, $S B P$ systolic blood pressure

*Defined as patients having a history of hypertension receiving antihypertensive medications within 4 weeks prior to screening, with mean sitting systolic blood pressure (msSBP) ranging from $\geq 150$ to $<180 \mathrm{mmHg}$ at randomization and $\geq 140$ to $<180 \mathrm{mmHg}$ at the visit immediately before randomization

**Defined as patients having a history of hypertension who had not been taking any antihypertensive medications for at least 4 weeks prior to screening, and had msSBP ranging from $\geq 150$ to $<180 \mathrm{mmHg}$ at both screening and randomization

\#Newly diagnosed hypertensive patients who had never taken any antihypertensive medications
(Table 2). While olmesartan provided similar msPP reductions in elderly and nonelderly patients, both doses of sacubitril/valsartan resulted in a numerically greater reduction in msPP in elderly patients than in nonelderly patients.

After 8 weeks of treatment, the mean change in pulse rate was $1.7,0.7$, and $0.9 \mathrm{bpm}$ with sacubitril/valsartan $200 \mathrm{mg}$, sacubitril/valsartan $400 \mathrm{mg}$, and olmesartan $20 \mathrm{mg}$, respectively.

\section{Blood pressure control}

At Week 8, a higher proportion of patients achieved overall BP control with both doses of sacubitril/valsartan than with olmesartan (Fig. 3). Similarly, the percentage of patients who achieved an SBP response $(\mathrm{msSBP}<140 \mathrm{mmHg}$ or a reduction from baseline $\geq 20 \mathrm{mmHg}$ ) and a DBP response $(\mathrm{msDBP}<90 \mathrm{mmHg}$ or a reduction from baseline $\geq 10$ $\mathrm{mmHg}$ ) was also greater in the sacubitril/valsartan treatment 


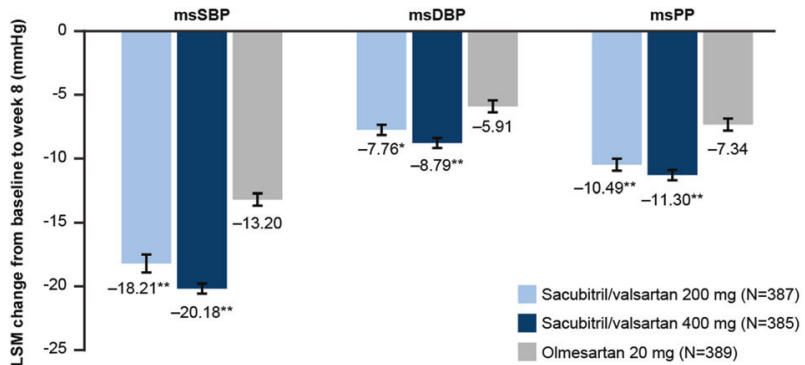

Fig. 2 Change from baseline in msSBP, msDBP, and msPP at Week 8 (full analysis set). $* P=0.001 ; * * P<0.001$ vs. olmesartan. LSM changes from baseline, standard errors, and $P$ values calculated using ANCOVA with baseline as a covariate; error bars represent standard error; endpoint represents data at Week 8 or the last observation carried forward; $N$ is the number of patients who had values at both baseline and the endpoint. ANCOVA analysis of covariance, BP blood pressure, LSM least squares mean, msDBP mean sitting diastolic BP, msPP mean sitting pulse pressure, msSBP mean sitting systolic BP

groups than in the olmesartan group (Fig. 3). As a post hoc analysis, we assessed the proportion of patients achieving BP control as defined by the $2019 \mathrm{JSH}$ guideline (msSBP/ msDBP $<130 / 80 \mathrm{mmHg}$ for $<75$ years old and $<140 / 90$ for $\geq 75$ years old). A higher proportion of patients achieved BP control with sacubitril/valsartan $400 \mathrm{mg}$ than with olmesartan $20 \mathrm{mg}$ ( $21.8 \%$ vs. $14.4 \%$, odds ratio [OR] $1.77,95 \%$ CI $[1.21,2.59])$. The proportion of patients who achieved BP control with sacubitril/valsartan $200 \mathrm{mg}$ was $17.6 \%$, vs. $14.4 \%$ in the olmesartan 20-mg group (OR $1.28,95 \%$ CI $[0.86,1.89])$.

\section{Safety}

The adverse events occurring in $\geq 1.0 \%$ of patients in any treatment group are summarized in Table 3. Overall, the incidence of AEs and SAEs leading to discontinuation was numerically more frequent in patients treated with olmesartan than in those treated with either dose of sacubitril/ valsartan. The incidence of AEs was comparable across age groups, with no age-specific trends observed.

Nasopharyngitis was the most common AE, with a similar incidence in all groups. Only one event of hypotension ( $0.3 \%$ in the sacubitril/valsartan 400 -mg group) was reported in this study. One event of angioedema $(0.3 \%)$ was reported in the olmesartan group, but no angioedema was reported in either sacubitril/valsartan dose group. Generally, most of the AEs that occurred during the 8-week treatment period were infrequent, mild, and transient.

During the 8-week treatment period, nine patients experienced SAEs: $0.3 \%(1 / 387)$ in the sacubitril/valsartan 200-mg group (subarachnoid hemorrhage), $0.3 \%$ (1/385) in the sacubitril/valsartan 400-mg group (arteriosclerosis of the coronary artery and hepatobiliary disease), and 1.8\% (7/ 389 ) in the olmesartan group (alanine aminotransferase

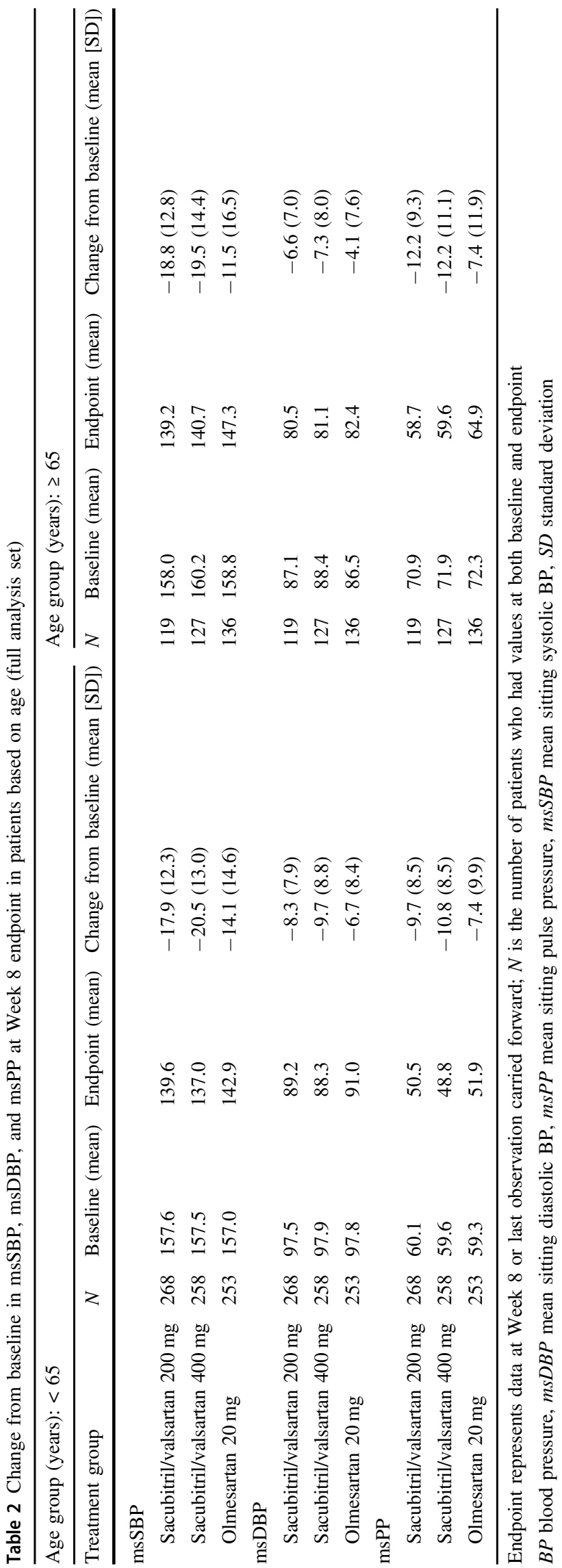




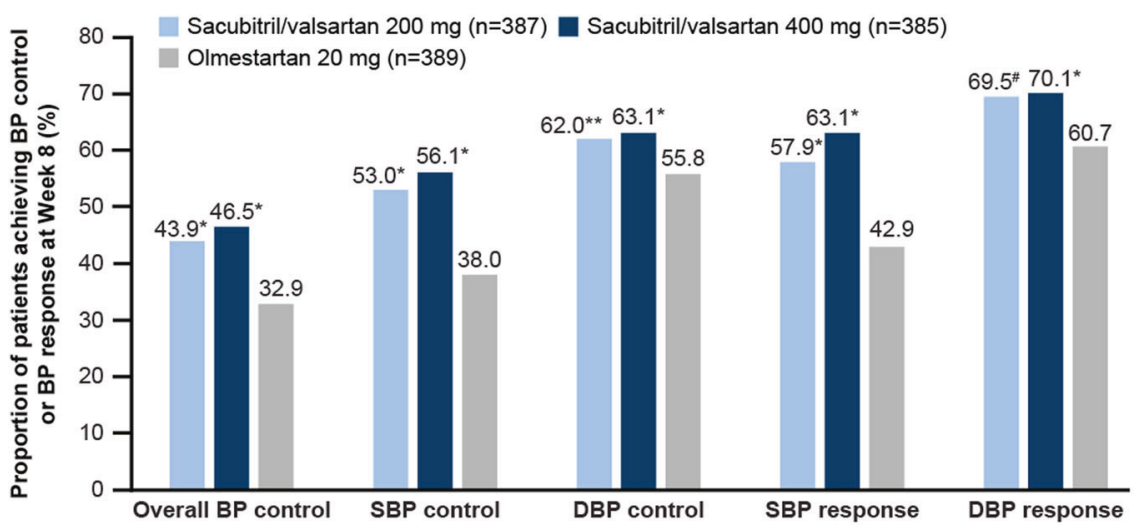

Fig. 3 Proportion of patients who achieved overall BP, systolic and diastolic blood pressure control and response at the Week 8 endpoint (full analysis set). $* P<0.001$ vs. olmesartan; $* * P=0.019$ vs. olmesartan; ${ }^{\#} P=0.002$ vs. olmesartan. $P$ values obtained from a logistic regression model with treatment as a factor and baseline value (msSBP for overall BP control and SBP control/response, msDBP for DBP control/response) as a covariate; $N$ is the number of patients who have values

increased, bile duct stone, cataract, cerebral infarction, osteoarthritis, radius fracture, and supraventricular tachycardia). No deaths occurred during the study.

During the 8-week treatment period, the mean changes from baseline in laboratory values were generally small. Potassium values $>5.5 \mathrm{mmol} / \mathrm{L}$ were reported in $1.8 \%$ ( $7 /$ $387), 1.6 \%(6 / 385)$, and $0.8 \%$ (3/388) of patients treated with sacubitril/valsartan $200 \mathrm{mg}$ and $400 \mathrm{mg}$ and olmesartan $20 \mathrm{mg}$, respectively, with one patient in the sacubitril/valsartan 400-mg group experiencing a potassium value $\geq 6.0$ $\mathrm{mmol} / \mathrm{L}$. In most of these patients, potassium levels returned to the normal range at the last study visit without any study medication disruption. Potassium values $<3.5 \mathrm{mmol} / \mathrm{L}$ were reported in one patient treated with sacubitril/valsartan 200 $\mathrm{mg}$, two treated with sacubitril/valsartan $400 \mathrm{mg}$, and one treated with olmesartan $20 \mathrm{mg}$. Blood urea nitrogen values $>14.28 \mathrm{mmol} / \mathrm{L}$ and sodium values $<130 \mathrm{mmol} / \mathrm{L}$ were reported for one patient in the sacubitril/valsartan 200-mg group; no patients in any treatment group showed a creatinine value $>176.8 \mu \mathrm{mol} / \mathrm{L}$. Mean decreases in uric acid were observed with sacubitril/valsartan $200 \mathrm{mg}(-16.0$ $\mu \mathrm{mol} / \mathrm{L})$ and $400 \mathrm{mg}(-28.1 \mu \mathrm{mol} / \mathrm{L})$, which were numerically greater than those observed with olmesartan $20 \mathrm{mg}$ $(-1.8 \mu \mathrm{mol} / \mathrm{L})$.

\section{Discussion}

In this phase III study, sacubitril/valsartan, a first-in-class ARNI, demonstrated superior reductions in clinical BP compared with olmesartan while showing comparable safety and tolerability in Japanese patients with hypertension. Sacubitril/valsartan $200 \mathrm{mg}$ and $400 \mathrm{mg}$ provided at both baseline and the endpoint; endpoint represents data at Week 8 or the last observation carried forward. Overall, BP control was defined as $\mathrm{msSBP} / \mathrm{msDBP}<140 / 90 \mathrm{mmHg}$, SBP control as $<140 \mathrm{mmHg}$, DBP control as $<90 \mathrm{mmHg}$, SBP response as $<140 \mathrm{mmHg}$ or a reduction from baseline $\geq 20 \mathrm{mmHg}$, and DBP response as $<90 \mathrm{mmHg}$ or a reduction from baseline $\geq 10 \mathrm{mmHg}$. BP blood pressure, DBP diastolic $\mathrm{BP}$, ms mean sitting, SBP systolic blood pressure

superior efficacy to olmesartan $20 \mathrm{mg}$ in reducing $\mathrm{msSBP}$ by $\sim 5 \mathrm{mmHg}$ and $7 \mathrm{mmHg}$, respectively. These reductions in $\mathrm{msSBP}$ are clinically meaningful, as every $10-\mathrm{mmHg}$ reduction in SBP is known to reduce the risk of major CV disease events by $20 \%$, coronary heart disease by $17 \%$, stroke by $27 \%$, heart failure by $28 \%$, and all-cause mortality by $13 \%$ [29]. These observations suggest that treatment with sacubitril/valsartan could substantially contribute to improving the clinical outcome of patients with hypertension.

Both sacubitril/valsartan doses were well tolerated, even in elderly patients. Moreover, no association was found between the $\mathrm{AE}$ rate and the dose of sacubitril/valsartan. The frequencies of discontinuations and SAEs were numerically lower in the sacubitril/valsartan groups than in the olmesartan group, and there were no deaths or reports of angioedema in either of the sacubitril/valsartan groups.

These results support the BP-lowering efficacy and safety of sacubitril/valsartan for the treatment of hypertension and are consistent with previous findings from studies in Asian patients [18], as well as findings from phase II and III studies in Western and Asian patients with mild to moderate essential hypertension [7, 17, 30]. Of particular note, the beneficial effects of sacubitril/valsartan on clinical measurements of SBP and PP were consistent across these studies. The subgroup analysis by age showed numerically greater differences in reductions from baseline in SBP and PP between sacubitril/valsartan and olmesartan in elderly patients than in nonelderly patients, without any safety concern. These observations are in accordance with an earlier study that demonstrated benefits of sacubitril/valsartan over olmesartan in elderly Asian patients with systolic hypertension [28]. Since increased SBP and PP have 
Table 3 Number (\%) of patients with adverse events $\geq 1 \%$ in any group during the 8-week treatment period (safety set)

\begin{tabular}{|c|c|c|c|}
\hline Preferred term & $\begin{array}{l}\text { Sacubitril/ } \\
\text { valsartan } \\
200 \mathrm{mg} \\
N=387 \\
n(\%)\end{array}$ & $\begin{array}{l}\text { Sacubitril/ } \\
\text { valsartan } \\
400 \mathrm{mg} \\
N=385 \\
n(\%)\end{array}$ & $\begin{array}{l}\text { Olmesartan } \\
20 \mathrm{mg} \\
N=389, \\
n(\%)\end{array}$ \\
\hline Any AEs & $135(34.9)$ & $136(35.3)$ & $152(39.1)$ \\
\hline AE discontinuations & $7(1.8)$ & $6(1.6)$ & $12(3.1)$ \\
\hline $\begin{array}{l}\text { Drug-related AE } \\
\text { discontinuations }\end{array}$ & $2(0.5)$ & $2(0.5)$ & $4(1.0)$ \\
\hline SAEs & $1(0.3)$ & $1(0.3)$ & $7(1.8)$ \\
\hline SAE discontinuations & $1(0.3)$ & $1(0.3)$ & $4(1.0)$ \\
\hline \multicolumn{4}{|l|}{ Common $\mathrm{AEs}^{\dagger}$} \\
\hline Nasopharyngitis & $48(12.4)$ & $47(12.2)$ & $46(11.8)$ \\
\hline Influenza & $1(0.3)$ & $5(1.3)$ & $1(0.3)$ \\
\hline Back pain & 0.0 & $5(1.3)$ & $1(0.3)$ \\
\hline Pharyngitis & $5(1.3)$ & $4(1.0)$ & $1(0.3)$ \\
\hline $\begin{array}{l}\text { Upper respiratory } \\
\text { tract infection }\end{array}$ & $2(0.5)$ & $4(1.0)$ & $2(0.5)$ \\
\hline Dermatitis contact & $1(0.3)$ & $4(1.0)$ & $1(0.3)$ \\
\hline Headache & $7(1.8)$ & $3(0.8)$ & $4(1.0)$ \\
\hline $\begin{array}{l}\text { Blood creatine } \\
\text { phosphokinase } \\
\text { increased }\end{array}$ & $4(1.0)$ & $3(0.8)$ & $4(1.0)$ \\
\hline $\begin{array}{l}\text { Blood bilirubin } \\
\text { increased }\end{array}$ & $2(0.5)$ & $3(0.8)$ & $4(1.0)$ \\
\hline Dizziness & $5(1.3)$ & $2(0.5)$ & $3(0.8)$ \\
\hline Cystitis & $4(1.0)$ & $2(0.5)$ & $1(0.3)$ \\
\hline Diarrhea & $2(0.5)$ & $1(0.3)$ & $5(1.3)$ \\
\hline $\begin{array}{l}\text { Alanine } \\
\text { aminotransferase } \\
\text { increased }\end{array}$ & $1(0.3)$ & 0.0 & $4(1.0)$ \\
\hline Hypertension & $1(0.3)$ & 0.0 & $4(1.0)$ \\
\hline $\begin{array}{l}\text { Hepatic function } \\
\text { abnormal }\end{array}$ & 0.0 & 0.0 & $5(1.3)$ \\
\hline
\end{tabular}

AEs are sorted in descending frequency, as reported for sacubitril/ valsartan $400 \mathrm{mg}$. A patient with multiple AEs within a primary system organ class is counted only once

$A E$ adverse event, $S A E$ serious adverse event

${ }^{\dagger} \geq 1 \%$ in any treatment group

been identified as important $\mathrm{CV}$ risk factors in aging patients and lowering elevated SBP and PP has been shown to improve $\mathrm{CV}$ outcomes, our results suggest that treatment with sacubitril/valsartan may have a favorable effect on CV risk, irrespective of age group. A favorable benefit-risk profile of sacubitril/valsartan compared with enalapril in reducing heart failure hospitalization and mortality in all age groups was also observed in an analysis from the PARADIGM-HF study in patients with HFrEF. Sacubitril/ valsartan was also superior to enalapril in preventing the deterioration of health-related quality of life across age ranges, even in the elderly group [31].
Asian populations may have differing levels of CV risk compared to Western populations. For example, a higher incidence of stroke than of coronary artery disease has been observed in Asian populations [32], and the association of raised BP with the risk of stroke appears to be stronger in Asian than Western populations [33]. In addition, Asian populations generally have a higher salt intake and are genetically more likely to have salt sensitivity than Western populations [34, 35]. High salt intake adversely impacts the ability of RAAS blockers such as olmesartan to lower BP. Due to its ability to inhibit neprilysin and through its multiple modes of action, sacubitril/valsartan is likely to be more potent in lowering BP, especially in populations with high salt intake [36]. Thus, the findings of this study in the Japanese population, in combination with the results of a similar study in the Chinese population [30], suggest promising clinical benefits for sacubitril/valsartan in Asian populations.

With aging, arteries gradually lose their elasticity, primarily due to collagen deposition and elastin depletion, resulting in increased peak SBP. Elevated PP is an indicator of vascular stiffness and is a strong predictor of risk associated with adverse $\mathrm{CV}$ events, including stroke, myocardial infarction, heart failure, CV disease, and CV mortality. Sacubitril/valsartan provided greater reductions in msPP than olmesartan in the current study, especially in elderly patients. These observations are further strengthened by the results of the PARAMETER study, which showed the superiority of sacubitril/valsartan $400 \mathrm{mg}$ vs. olmesartan 40 $\mathrm{mg}$ in reducing clinical and ambulatory central aortic and brachial pressures in elderly patients with systolic hypertension and stiff arteries [37]. Such results suggest beneficial effects on arterial stiffness, an underlying cause of systolic hypertension. The reduction in PP observed in elderly patients in these studies could be due to a modulation of arterial wall elasticity, possibly brought about by antihypertrophic and antifibrotic properties of sacubitril/ valsartan [38]. Simultaneous neprilysin inhibition and angiotensin II receptor-1 blockade have been shown to have antihypertrophic and antifibrotic effects in preclinical models, attenuating adverse tissue remodeling [38]. Such complementary neurohormonal modulation may provide an effective therapeutic approach to addressing arterial stiffness. In addition, in patients with HFrEF who were hospitalized for acute decompensated heart failure, sacubitril/ valsartan treatment resulted in a rapid reduction in NTproBNP levels, which was evident as early as one week [39]. This rapid and greater NT-proBNP reduction may also likely result in improved ventricular-vascular coupling. Sacubitril/valsartan may also augment the vasodilatory effects of natriuretic peptides, thereby reducing SBP and PP. Whether there are additional mechanistic factors contributing to the reduction of PP and SBP with sacubitril/ valsartan and whether a longer treatment duration results in 
greater BP and PP reductions due to additional beneficial effects on arterial wall elasticity, particularly in elderly individuals, need further evaluation.

This study was limited to the assessment of peripheral BP that was measured at the clinic. Although reductions in SBP are associated with improved CV outcomes, the potential benefit of sacubitril/valsartan on 24-hour BP reduction and $\mathrm{CV}$ and renal outcomes in a hypertensive population remains to be elucidated.

\section{Conclusion}

The results of this pivotal phase III study showed that treatment with sacubitril/valsartan is effective and generally well tolerated in Japanese patients with mild to moderate essential hypertension. Sacubitril/valsartan $200 \mathrm{mg}$ and 400 $\mathrm{mg}$ once daily showed BP-lowering effects that were superior to those of olmesartan $20 \mathrm{mg}$.

Acknowledgements The authors acknowledge all investigators at the participating centers and all patients for their commitment to the study, which was supported by Novartis Pharma AG. The authors would also like to thank Hyosung Kim and Sandra Thompson, former employees of Novartis Pharmaceuticals and Novartis Pharma AG, for their statistical support at the time this study was conducted. We would like to thank Nagabhushana Ananthamurthy, Sreedevi Boggarapu, and Kripi Syal (Scientific Services, Novartis Healthcare Pvt. Ltd, Hyderabad, India) for providing medical writing and editorial support.

Funding The study was funded by Novartis AG, Basel, Switzerland.

\section{Compliance with ethical standards}

Conflict of interest HR served as the external medical expert for this study and has received consulting fees from Novartis Pharmaceuticals. KK has received speaker honoraria and consulting fees from Novartis Pharmaceuticals, and has received scholarship and honoraria from Daiichi Sankyo outside the submitted work. MY, TS, and HG are employees of Novartis Pharma K. K., Tokyo, Japan. JZ was an employee of Novartis Pharmaceuticals Corporation, East Hanover, NJ, USA, during the conduct of this study.

Publisher's note Springer Nature remains neutral with regard to jurisdictional claims in published maps and institutional affiliations.

Open Access This article is licensed under a Creative Commons Attribution 4.0 International License, which permits use, sharing, adaptation, distribution and reproduction in any medium or format, as long as you give appropriate credit to the original author(s) and the source, provide a link to the Creative Commons licence, and indicate if changes were made. The images or other third party material in this article are included in the article's Creative Commons licence, unless indicated otherwise in a credit line to the material. If material is not included in the article's Creative Commons licence and your intended use is not permitted by statutory regulation or exceeds the permitted use, you will need to obtain permission directly from the copyright holder. To view a copy of this licence, visit http://creativecommons. org/licenses/by/4.0/.

\section{References}

1. Kabutoya T, Hoshide S, Kario K. Asian management of hypertension: current status, home blood pressure, and specific concerns in Japan. J Clin Hypertens (Greenwich). 2020;22:486-92.

2. Soenarta AA, Buranakitjaroen P, Chia YC, Chen CH, Nailes J, Hoshide $\mathrm{S}$, et al. An overview of hypertension and cardiac involvement in Asia: Focus on heart failure. J Clin Hypertens (Greenwich). 2020;22:423-30.

3. Ogihara T, Kikuchi K, Matsuoka H, Fujita T, Higaki J, Horiuchi $\mathrm{M}$, et al. The Japanese Society of Hypertension Guidelines for the Management of Hypertension (JSH 2009). Hypertens Res. 2009;32:3-107.

4. Umemura S, Arima H, Arima S, Asayama K, Dohi Y, Hirooka Y, et al. The Japanese Society of Hypertension Guidelines for the Management of Hypertension (JSH 2019). Hypertens Res. 2019;42:1235-481.

5. Mori H, Ukai H, Yamamoto H, Saitou S, Hirao K, Yamauchi M, et al. Current status of antihypertensive prescription and associated blood pressure control in Japan. Hypertens Res. 2006;29:143-51.

6. Gu J, Noe A, Chandra P, Al-Fayoumi S, Ligueros-Saylan M, Sarangapani R, et al. Pharmacokinetics and pharmacodynamics of LCZ696, a novel dual-acting angiotensin receptor-neprilysin inhibitor (ARNi). J Clin Pharm. 2010;50:401-14.

7. Ruilope LM, Dukat A, Bohm M, Lacourciere Y, Gong J, Lefkowitz MP. Blood-pressure reduction with LCZ696, a novel dualacting inhibitor of the angiotensin II receptor and neprilysin: a randomised, double-blind, placebo-controlled, active comparator study. Lancet. 2010;375:1255-66.

8. Novartis. Entresto ${ }^{\mathrm{TM}}$ (sacubitril and valsartan): US pescribing information. http://www.pharma.us.novartis.com/product/pi/pdf/ entresto.pdf. Accessed 20 April.

9. EMA. Entresto (sacubitril/valsartan) product information. http://www.ema.europa.eu/ema/index.jsp?curl=pages/medicines/ human/medicines/004062/human_med_001929.jsp\&mid= WC0b01ac058001d124. Accessed 20 April.

10. Kario K. The Sacubitril/Valsartan, a first-in-class, angiotensin receptor neprilysin inhibitor (ARNI): potential uses in hypertension, heart failure, and beyond. Curr Cardiol Rep. 2018;20:5.

11. McMurray JJ, Packer M, Desai AS, Gong J, Lefkowitz MP, Rizkala AR, et al. Angiotensin-neprilysin inhibition versus enalapril in heart failure. N. Engl J Med. 2014;371:993-1004.

12. Novartis Pharma and Otsuka Pharmaceutical Co. L. Novartis Pharma obtains manufacturing and marketing approval in Japan for Entresto ${ }^{\varpi}$ tablet as angiotensin receptor neprilysin inhibitor (ARNI) for chronic heart failure. https://www.otsuka.co.jp/en/company/new sreleases/2020/20200629_3.html. Accessed 11 June.

13. Administration USFaD. Highlights of prescribing information: Entresto. https://www.accessdata.fda.gov/drugsatfda_docs/label/ 2021/207620s0181bl.pdf. Accessed 11 June.

14. Gardner DG, Chen S, Glenn DJ, Grigsby CL. Molecular biology of the natriuretic peptide system: implications for physiology and hypertension. Hypertension. 2007;49:419-26.

15. Bavishi C, Messerli FH, Kadosh B, Ruilope LM, Kario K. Role of neprilysin inhibitor combinations in hypertension: insights from hypertension and heart failure trials. Eur Heart J. 2015;36:1967-73.

16. Lin DS, Wang TD, Buranakitjaroen $\mathrm{P}$, Chen $\mathrm{CH}$, Cheng HM, Chia YC, et al. Angiotensin receptor neprilysin inhibitor as a novel antihypertensive drug: evidence from Asia and around the globe. J Clin Hypertens (Greenwich). 2021;23:556-67.

17. Kario K, Sun N, Chiang FT, Supasyndh O, Baek SH, InubushiMolessa A, et al. Efficacy and safety of LCZ696, a first-in-class angiotensin receptor neprilysin inhibitor, in Asian patients with hypertension: a randomized, double-blind, placebo-controlled study. Hypertension. 2014;63:698-705. 
18. Supasyndh O, Sun N, Kario K, Hafeez K, Zhang J. Long-term (52-week) safety and efficacy of Sacubitril/valsartan in Asian patients with hypertension. Hypertens Res. 2017;40:472-6.

19. Kario K, Tamaki Y, Okino N, Gotou H, Zhu M, Zhang J. LCZ696, a first-in-class angiotensin receptor-neprilysin inhibitor: the first clinical experience in patients with severe hypertension. $\mathbf{J}$ Clin Hypertens (Greenwich). 2016;18:308-14.

20. Ito S, Satoh M, Tamaki Y, Gotou H, Charney A, Okino N, et al. Safety and efficacy of LCZ696, a first-in-class angiotensin receptor neprilysin inhibitor, in Japanese patients with hypertension and renal dysfunction. Hypertens Res. 2015;38:269-75.

21. Smith DH, Dubiel R, Jones M. Use of 24-hour ambulatory blood pressure monitoring to assess antihypertensive efficacy: a comparison of olmesartan medoxomil, losartan potassium, valsartan, and irbesartan. Am J Cardiovasc Drugs. 2005;5:41-50.

22. Zannad F, Fay R. Blood pressure-lowering efficacy of olmesartan relative to other angiotensin II receptor antagonists: an overview of randomized controlled studies. Fundam Clin Pharm. 2007;21:181-90.

23. Nakajima T, Oh A, Saita S, Yoshida T, Ohishi M, Nishigaki N. Comparative effectiveness of angiotensin II receptor blockers in patients with hypertension in Japan-systematic review and network meta-analysis. Circ Rep. 2020;2:576-86.

24. Tsoi B, Akioyamen LE, Bonner A, Frankfurter C, Levine M, Pullenayegum E, et al. Comparative efficacy of angiotensin II antagonists in essential hypertension: systematic review and network meta-analysis of randomised controlled trials. Heart Lung Circ. 2018;27:666-82.

25. Wang L, Zhao JW, Liu B, Shi D, Zou Z, Shi XY. Antihypertensive effects of olmesartan compared with other angiotensin receptor blockers: a meta-analysis. Am J Cardiovasc Drugs. 2012;12:335-44.

26. Segura J, Ruilope LM. Dual-acting angiotensin receptorneprilysin inhibition. Curr Hypertens Rep. 2011;13:74-8.

27. Cheung DG, Aizenberg D, Gorbunov V, Hafeez K, Chen CW, Zhang J. Efficacy and safety of sacubitril/valsartan in patients with essential hypertension uncontrolled by olmesartan: a randomized, double-blind, 8-week study. J Clin Hypertens. 2018;20:150-8.

28. Supasyndh O, Wang J, Hafeez K, Zhang Y, Zhang J, Rakugi H. Efficacy and Safety of Sacubitril/Valsartan (LCZ696) compared with Olmesartan in Elderly Asian Patients $(>/=65$ Years) with systolic hypertension. Am J Hypertens. 2017;30:1163-9.
29. Ettehad D, Emdin CA, Kiran A, Anderson SG, Callender T, Emberson $\mathrm{J}$, et al. Blood pressure lowering for prevention of cardiovascular disease and death: a systematic review and metaanalysis. Lancet. 2016;387:957-67.

30. Huo Y, Li W, Webb R, Zhao L, Wang Q, Guo W. Efficacy and safety of sacubitril/valsartan compared with olmesartan in Asian patients with essential hypertension: a randomized, double-blind, 8-week study. J Clin Hypertens (Greenwich). 2019;21:67-76.

31. Jhund PS, Fu M, Bayram E, Chen CH, Negrusz-Kawecka M, Rosenthal A, et al. Efficacy and safety of LCZ696 (sacubitrilvalsartan) according to age: insights from PARADIGM-HF. Eur Heart J. 2015;36:2576-84.

32. Ueshima H, Sekikawa A, Miura K, Turin TC, Takashima N, Kita $\mathrm{Y}$, et al. Cardiovascular disease and risk factors in Asia: a selected review. Circulation. 2008;118:2702-9.

33. Perkovic V, Huxley R, Wu Y, Prabhakaran D, MacMahon S. The burden of blood pressure-related disease: a neglected priority for global health. Hypertension. 2007;50:991-7.

34. Katsuya T, Ishikawa K, Sugimoto K, Rakugi H, Ogihara T. Salt sensitivity of Japanese from the viewpoint of gene polymorphism. Hypertens Res. 2003;26:521-5.

35. Stamler J. The INTERSALT Study: background, methods, findings, and implications. Am J Clin Nutr. 1997;65:626S-42S.

36. Kusaka H, Sueta D, Koibuchi N, Hasegawa Y, Nakagawa T, Lin B, et al. LCZ696, Angiotensin II Receptor-Neprilysin Inhibitor, Ameliorates high-salt-induced hypertension and cardiovascular injury more than Valsartan Alone. Am J Hypertens. 2015;28:1409-17.

37. Williams B, Cockcroft JR, Kario K, Zappe DH, Brunel PC, Wang Q, et al. Effects of Sacubitril/Valsartan versus olmesartan on central hemodynamics in the elderly with systolic hypertension: The PARAMETER Study. Hypertension.2017;69:411-20.

38. von Lueder TG, Wang BH, Kompa AR, Huang L, Webb R, Jordaan P, et al. Angiotensin receptor neprilysin inhibitor LCZ696 attenuates cardiac remodeling and dysfunction after myocardial infarction by reducing cardiac fibrosis and hypertrophy. Circ Heart Fail. 2015;8:71-8.

39. Velazquez EJ, Morrow DA, DeVore AD, Duffy CI, Ambrosy $\mathrm{AP}$, McCague K, et al. Angiotensin-neprilysin inhibition in acute decompensated heart failure. N. Engl J Med. 2019;380:539-48. 